\title{
A Note on Separability of the Profit Function
}

\author{
Rolf Färe ${ }^{1,2}$, Giannis Karagiannis ${ }^{3}$ \\ ${ }^{1}$ Department of Economics, Oregon State University, Corvallis, OR, USA \\ ${ }^{2}$ Department of Agricultural \& Resource Economics, Oregon State University, Corvallis, OR, USA \\ ${ }^{3}$ Department of Economics, University of Macedonia, Thessaloniki, Greece \\ Email: rolf.fare@oregonstate.edu, karagian@uom.gr
}

Received 2 April 2014; revised 5 May 2014; accepted 6 June 2014

Copyright (C) 2014 by authors and Scientific Research Publishing Inc.

This work is licensed under the Creative Commons Attribution International License (CC BY).

http://creativecommons.org/licenses/by/4.0/

\begin{abstract}
Based on the concept of translation elasticity we restate in this note the Färe and Grosskopf's [1] conditions for additive separability of the profit function. We show that for the profit function to be additively separable, the technology must satisfy both simultaneous input-and-output translation homotheticity and graph translation homotheticity.
\end{abstract}

\section{Keywords}

Separability, Profit Function, Directional Distance Function, Graph Translation Homotheticity, Simultaneous Input-and-Output Translation Homotheticity

\section{Review}

Färe and Grosskopf [1] derived conditions on production technology which are required for the profit function to be additively separable into a revenue function component depending only on output prices and a cost function component depending only on input prices. In particular, they showed that simultaneous input-and-output translation homotheticity of production technology implies additive separability of the profit function and vice versa, for some input and output direction vectors such as that the inner product of output prices and the output direction vector is equal to the inner product of inputs prices and the input direction vector. In the light of recent work by Balk, Färe and Karagiannis [2] one can verify that the latter condition implies indeed graph translation homotheticity. We may then restate Färe and Grosskopf's [1] proposition as following: the profit function is additively separable if and only if technology is simultaneous input-and-output translation homothetic and exhibits graph translation homotheticity.

Let $x \in R_{+}^{n}$ denote a vector of inputs and $y \in R_{+}^{m}$, a vector of outputs with $w \in R_{++}^{n}$ and $p \in R_{++}^{m}$ being their corresponding price vectors. The technology is defined in terms of $T=\{(x, y): x$ can produce $y\}$, which is 
closed, allows for free disposability of inputs and outputs, and it contains $\left(0^{n}, 0^{m}\right)$. Then the directional technology distance function, which is the negative of the shortage function introduced by Luenberger [3], is given as (see Chambers, Chung and Färe [4]):

$$
\overrightarrow{\boldsymbol{D}}^{\mathrm{T}}\left(x, y ; g_{x}, g_{y}\right)=\sup \left\{\delta:\left(x-\delta g_{x}, y+\delta g_{y}\right) \in T\right\}
$$

and has the following properties: first, $\vec{D}^{\mathrm{T}}\left(x, y ; g_{x}, g_{y}\right) \geq 0$ if and only if $(x, y) \in T$ assuming $(x, y)$ are freely disposable; second, it is non-decreasing in $x$ if inputs are freely disposable; third, it is non-increasing in $y$ if outputs are freely disposable; fourth, it is concave in $x$ and $y$ if $\mathrm{T}$ is convex; fifth,

$\overrightarrow{\boldsymbol{D}}^{\mathrm{T}}\left(x-\gamma g_{x}, y+\gamma g_{y} ; g_{x}, g_{y}\right)=\overrightarrow{\boldsymbol{D}}^{\mathrm{T}}\left(x, y ; g_{x} \cdot g_{y}\right)-\gamma$ (translation property); and sixth, it is homogeneous of degree -1 in the direction vector $\left(g_{x}, g_{y}\right) \in R_{+}^{n+m}$. The directional technology distance function is general enough and it contains all other forms of directional functions as special cases. In particular, $g_{y}=0$ results in the directional input distance function while $g_{x}=0$ gives rise to the directional output distance function.

Following Färe and Grosskopf [1], the technology is simultaneously input-and-output translation homothetic if the directional technology distance function takes the form:

$$
2 \overrightarrow{\boldsymbol{D}}^{\mathrm{T}}\left(x, y ; g_{x}, g_{y}\right)=\overrightarrow{\boldsymbol{D}}^{O}\left(1, y ; g_{y}\right)+\overrightarrow{\boldsymbol{D}}^{\mathrm{I}}\left(x, 1 ; g_{x}\right)
$$

where $\overrightarrow{\boldsymbol{D}}^{O}\left(1, y ; g_{y}\right)$ and $\overrightarrow{\boldsymbol{D}}^{I}\left(x, 1 ; g_{x}\right)$ are the directional output and input distance functions, respectively. On the other hand, additive separability of the profit function implies that [5]:

$$
\pi(w, p)=R(p, 1)-C(w, 1)
$$

In order to prove that (1) implies (2) and vice versa, Färe and Grosskopf [1] had to chose $g_{x}$ and $g_{y}$ such that $w^{\prime} g_{x}=p^{\prime} g_{y}$, i.e., the value of output direction vector is equal to the value of input direction vector, which at a first instance may be seen as a convenient normalization. Nevertheless, based on recent work by Balk, Färe and Karagiannis [2] we can now claim that this is far from being just a convenient normalization. Quite the opposite: it is related to a particular property of production technology, namely graph translation homotheticity. To see this we follow Balk, Färe and Karagiannis [2] in defining the translation elasticity as:

$$
\theta=-\frac{\left(\nabla_{x} \overrightarrow{\boldsymbol{D}}^{\mathrm{T}}\right)^{\prime} g_{x}}{\left(\nabla_{y} \overrightarrow{\boldsymbol{D}}^{\mathrm{T}}\right)^{\prime} g_{y}}
$$

which gives the maximal number of times the output direction vector $g_{y}$ is allowed by the technology to be added into output quantities when the input direction vector $g_{x}$ has been added a particular number of times into input quantities. From the duality between the profit function and the directional technology distance function we have (see Chambers, Chung and Färe [4]):

$$
\pi(p, w)=\max _{x, y}\left\{p^{\prime} y-w^{\prime} x+\overrightarrow{\mathbf{D}}^{\mathrm{T}}\left(x, y ; g_{x}, g_{y}\right)\left(p^{\prime} g_{y}+w^{\prime} g_{x}\right)\right\}
$$

with the corresponding first-order conditions being $-w+\nabla_{x} \overrightarrow{\boldsymbol{D}}^{\mathrm{T}}\left(p^{\prime} g_{y}+w^{\prime} g_{x}\right)=0$ and $p+\nabla_{y} \vec{D}^{\mathrm{T}}\left(p^{\prime} g_{y}+w^{\prime} g_{x}\right)=0$. By substituting them into (3) one can verify that $\theta=w^{\prime} g_{x} / p^{\prime} g_{y}$, namely that the translation elasticity is equal to the relative value of the input and the output direction vector. Then, constant returns to translation in the direction of $\left(g_{x}, g_{y}\right)$ imply that $\theta=1$ and thus, $w^{\prime} g_{x}=p^{\prime} g_{y}$. This in turn implies that $\left(\nabla_{x} \overrightarrow{\boldsymbol{D}}^{\mathrm{T}}\right)^{\prime} g_{x}+\left(\nabla_{y} \overrightarrow{\boldsymbol{D}}^{\mathrm{T}}\right)^{\prime} g_{y}=0$, i.e., graph translation homotheticity [6]. In addition, Briec and Kerstens [7] showed that in this case 


$$
2 \overrightarrow{\boldsymbol{D}}^{\mathrm{T}}\left(x, y ; g_{x}, g_{y}\right)=\overrightarrow{\boldsymbol{D}}^{O}\left(x, y ; g_{y}\right)=\overrightarrow{\boldsymbol{D}}^{I}\left(x, y ; g_{x}\right)
$$

Combining (1) and (4) results in the following form of the directional technology distance function:

$$
2 \overrightarrow{\boldsymbol{D}}^{\mathrm{T}}\left(x, y ; g_{x}, g_{y}\right)=\overrightarrow{\boldsymbol{D}}^{O}\left(1, y ; g_{y}\right)+\overrightarrow{\boldsymbol{D}}^{I}\left(x, 1 ; g_{x}\right)=\overrightarrow{\boldsymbol{D}}^{O}\left(x, y ; g_{y}\right)=\overrightarrow{\boldsymbol{D}}^{I}\left(x, y ; g_{x}\right)
$$

We can thus replace the requirement of $w^{\prime} g_{x}=p^{\prime} g_{y}$ in Färe and Grosskopf [1] conditions for the separability of the profit function with that of the last two equalities in (5).

\section{Conclusion}

In this note we have restated the directional distance function characterization of the technology required for additive separability of the profit function based on the concept of translation elasticity. We have shown in particular that for the profit function to be additively separable, the technology must satisfy both simultaneous input-and-output translation homotheticity and graph translation homotheticity.

\section{References}

[1] Färe, R. and Grosskopf, S. (2000) On Separability of the Profit Function. Journal of Optimization Theory and Applications, 105, 609-620. http://dx.doi.org/10.1023/A:1004693107475

[2] Balk, B.M., Färe, R. and Karagiannis, G. (2014) On Directional Scale Elasticities. Journal of Productivity Analysis. (forthcoming). http://dx.doi.org/10.1007/s11123-014-0399-6

[3] Luenberger, D.G. (1995) Microeconomic Theory. McGraw-Hill, New York.

[4] Chambers, R.G., Chung, Y. and Färe, R. (1998) Profit, Directional Distance Functions, and Nelrovian Efficiency. Journal of Optimization Theory and Applications, 98, 351-364. http://dx.doi.org/10.1023/A:1022637501082

[5] Lau, L.J. (1972) Profit Functions for Technologies with Multiple Inputs and Outputs. Review of Economics and Statistics, 54, 281-289. http://dx.doi.org/10.2307/1937989

[6] Chambers, R.G. (2002) Exact Nonradial Input, Output and Productivity Measurement. Economic Theory, 20, $751-765$. http://dx.doi.org/10.1007/s001990100231

[7] Briec, W. and Kerstens, K. (2004)A Luenberger-Hicks-Moorsteen Productivity Indicator: Its Relation to the HicksMoorsteen Productivity Index and the Luenberger Productivity Indicator. Economic Theory, 23, 925-939. http://dx.doi.org/10.1007/s00199-003-0403-2 
Scientific Research Publishing (SCIRP) is one of the largest Open Access journal publishers. It is currently publishing more than 200 open access, online, peer-reviewed journals covering a wide range of academic disciplines. SCIRP serves the worldwide academic communities and contributes to the progress and application of science with its publication.

Other selected journals from SCIRP are listed as below. Submit your manuscript to us via either submit@scirp.org or Online Submission Portal.
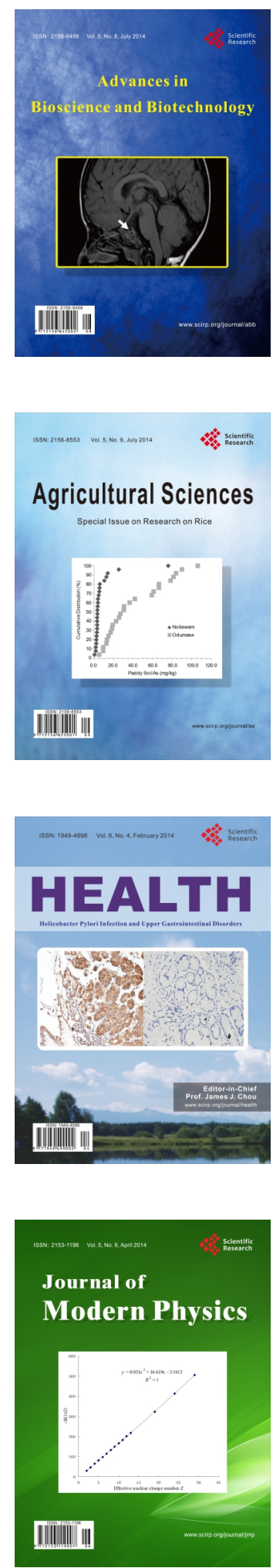
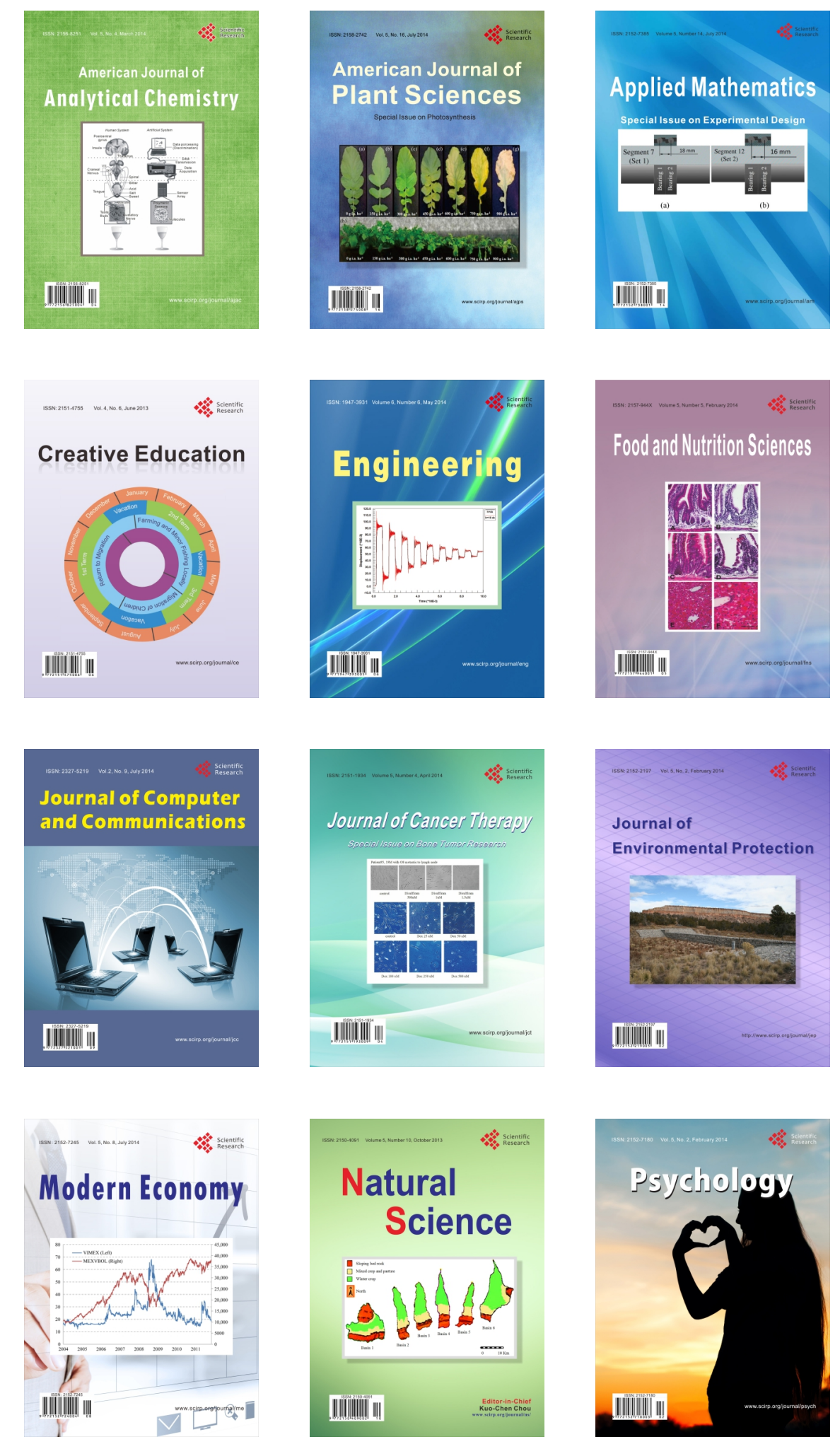